\title{
Efficacy and safety of cefazolin versus antistaphylococcal penicillins for the treatment of methicillin-susceptible Staphylococcus aureus bacteremia: a systematic review and meta-analysis
}

\author{
Changcheng Shi ${ }^{1,2+}$, Yubo Xiao ${ }^{3 \dagger}$, Qi Zhang ${ }^{2+}$, Qingyu Li ${ }^{1}$, Fei Wang ${ }^{1}$, Jing Wu ${ }^{4}$ and Nengming Lin ${ }^{1,2,5^{*}}$
}

\begin{abstract}
Background: Antistaphylococcal penicillins (ASPs) and cefazolin have become the most frequent choices for the treatment of methicillin-susceptible Staphylococcus aureus (MSSA) infections. However, the best therapeutic agent to treat MSSA bacteremia remains to be established.

Methods: We conducted a systematic review and meta-analysis to evaluate the efficacy and safety of these two regimens for the treatment of MSSA bacteremia. PubMed, EMBASE and the Cochrane Library from inception to February 2018 were searched. The primary outcome was mortality. The secondary outcomes included treatment failure, recurrence of bacteremia, adverse effects (AEs) and discontinuation due to AEs. Data were extracted and pooled odds ratios (ORs) and 95\% confidence intervals (Cls) were calculated.
\end{abstract}

Results: A total of ten observational studies met the inclusion criteria. The results indicate that compared to ASPs, cefazolin was associated with significant reduction in mortality $\left(\mathrm{OR}, 0.69 ; 95 \% \mathrm{Cl}, 0.58\right.$ to $\left.0.82 ;\left.\right|^{2}=3.4 \%\right)$ and clinical failure $\left(\mathrm{OR}, 0.56 ; 95 \% \mathrm{Cl}, 0.37\right.$ to $\left.0.85 ; \mathrm{I}^{2}=44.9 \%\right)$ without increasing the recurrence of bacteremia $(\mathrm{OR}, 1.12 ; 95 \% \mathrm{Cl}$, 0.94 to $\left.1.34 ;\left.\right|^{2}=0 \%\right)$. There were no significant differences for the risk of anaphylaxis $(\mathrm{OR}, 0.91 ; 95 \% \mathrm{Cl}, 0.36$ to 2.99 ; $\left.\mathrm{I}^{2}=0 \%\right)$ or hematotoxicity $\left(\mathrm{OR}, 0.56 ; 95 \% \mathrm{Cl}, 0.17\right.$ to $\left.1.88 ; \mathrm{I}^{2}=0 \%\right)$. However, nephrotoxicity $(\mathrm{OR}, 0.36 ; 95 \% \mathrm{Cl}, 0.16$ to $\left.0.81 ; I^{2}=0 \%\right)$ and hepatotoxicity $\left(\mathrm{OR}, 0.12 ; 95 \% \mathrm{Cl}, 0.04\right.$ to $\left.0.41 ; \mathrm{I}^{2}=0 \%\right)$ were significantly lower in the cefazolin group. Moreover, cefazolin was associated with lower probability of discontinuation due to AEs compared with the ASPs (OR, 0.24; 95\% Cl, 0.12 to $\left.0.48 ;\left.\right|^{2}=18 \%\right)$.

Conclusion: The results of present study favor the application of cefazolin and should be regarded as important evidence to help make clinical decisions in choosing a treatment option for treating MSSA bacteremia.

Keywords: Cefazolin, Antistaphylococcal penicillins, Methicillin-susceptible Staphylococcus aureus, Bacteremia, Metaanalysis

\footnotetext{
*Correspondence: Inm1013@163.com

${ }^{\dagger}$ Changcheng Shi, Yubo Xiao and Qi Zhang contributed equally to this work.Changcheng Shi, Yubo Xiao and Qi Zhang co-first authors.

'Department of Clinical Pharmacy, Affiliated Hangzhou First People's Hospital, Zhejiang University School of Medicine, Hangzhou, China

${ }^{2}$ Department of Clinical Pharmacy, Hangzhou First People's Hospital, Nanjing

Medical University, Hangzhou, China

Full list of author information is available at the end of the article
}

(c) The Author(s). 2018 Open Access This article is distributed under the terms of the Creative Commons Attribution 4.0 International License (http://creativecommons.org/licenses/by/4.0/), which permits unrestricted use, distribution, and reproduction in any medium, provided you give appropriate credit to the original author(s) and the source, provide a link to the Creative Commons license, and indicate if changes were made. The Creative Commons Public Domain Dedication waiver (http://creativecommons.org/publicdomain/zero/1.0/) applies to the data made available in this article, unless otherwise stated. 


\section{Background}

Staphylococcus aureus is the principal cause of community-acquired and nosocomial infections. Although more clinical research has focused on the methicillin-resistant Staphylococcus aureus (MRSA), bloodstream infections due to methicillin-susceptible Staphylococcus aureus (MSSA) remain a significant healthcare burden worldwide with high morbidity and mortality $[1,2]$.

Prevailing evidence has established the use of $\beta$-lactam antibiotics in preference to vancomycin as optimum therapy for MSSA bacteremia [3, 4]. According to the relevant clinical practice guidelines, cefazolin and antistaphylococcal penicillins (ASPs) such as nafcillin, oxacillin, and cloxacillin are the most frequent choices [5-8]. However, the optimal choice of $\beta$-lactam antibiotic for MSSA bacteremia is still unclear. To our knowledge, randomized control trials (RCTs) directly comparing clinical outcomes between cefazolin and ASPs for MSSA bacteremia are lacking, but data are emerging to support the role of cefazolin as a first-line agent for MSSA bacteremia [9, 10]. The aim of this meta-analysis was to summarize all the available evidence and compare the efficacy and safety of cefazolin versus ASPs for the treatment of MSSA bacteremia.

\section{Methods}

\section{Registry}

This systematic review and meta-analysis has been prospectively registered in PROSPERO with the registration no. CRD42018090547.

\section{Literature search strategy}

We searched PubMed, EMBASE and the Cochrane Library from inception to February 2018. The search terms were "(oxacillin OR nafcillin OR methicillin OR cloxacillin OR floxacillin OR dicloxacillin OR flucloxacillin OR antistaphylococcal penicillin OR semisynthetic penicillin) AND (methicillin-susceptible Staphylococcus aureus OR methicillin susceptible Staphylococcus aureus OR MSSA) AND (bacteremia OR bacteraemia OR bloodstream infection OR sepsis) AND cefazolin)". Reference lists of the relevant publications were searched for additional literature. No language or publication restriction were imposed.

\section{Inclusion criteria and study selection}

Two review authors independently reviewed the results to screen relevant studies for further assessment. Any discrepancy was resolved through discussion. Original studies included in our meta-analysis were required to meet the following criteria: (i) RCTs or observational designs, including cohort and case-control studies; (ii) comparing the efficacy or safety of treatment between cefazolin and ASPs for MSSA bacteremia in two groups of patients; (iii) at least one of the following outcomes: mortality, treatment failure, recurrence of bacteremia, adverse effects (AEs) and discontinuation due to AEs. Exclusion criteria were as follows: (i) no outcome data were available; (ii) studies investigating only cefazolin or ASPs; (iii) presented solely as abstract at scientific conferences; (iv) duplicate publications.

\section{Outcomes}

The primary outcome assessed in this meta-analysis was mortality. The secondary outcomes included treatment failure, recurrence of bacteremia, AEs and discontinued treatment due to AEs. While extracting data, we found that for 'mortality', some studies reported 'all-cause mortality', 'all-cause in-hospital mortality', 'over mortality' or 'bacteremia-associated mortality'. In our meta-analysis, all of these terms were regarded as approximate 'mortality'. When data for more than one endpoint were available, mortality in the main analysis was recorded at the latest point in the study (e.g., 90-day mortality had precedence over 30-day mortality). Treatment failure and other secondary outcomes were defined according to descriptions provided by each study.

\section{Data extraction and quality assessment}

The variables that were abstracted from each study included the investigator, publication year, study design, location, enrolment period, number of participants, patient characteristics (age, sex, disease severity, the source of infection), intervention and comparison, dose and duration of administration, and outcome measures. Data were extracted independently by two authors. Discrepancies were resolved in meetings. Because only observational studies were available for inclusion, the quality of the included publications was appraised based on the Newcastle-Ottawa scale (NOS), as recommended by the Cochrane Collaboration [11]. Each study was scored from 0 to 9, based on eight items within the three following domains: selection, comparability and exposure (or outcome) [12].

\section{Statistical analysis}

Pooled odds ratios (ORs) and 95\% confidence intervals (CIs) of all outcomes were used to determine whether there were significant differences between the compared data. Heterogeneity was evaluated using the $\mathrm{I}^{2}$ statistic and a value of $>50 \%$ was defined to indicate significant heterogeneity. If no significant heterogeneity was found, a fixed-effects model was used. Otherwise, a random-effect model was selected. Sensitivity analyses were undertaken by excluding each publication. Subgroup analyses were performed based on the study design, location, study period, time of mortality reporting and control group. 
Additionally, we presented separate subgroup analyses of adjusted or unadjusted estimates. Publication bias was assessed by generating funnel plots and tested used Begg's and Egger's asymmetry test. A $P$-value of $<0.05$ was considered statistically significant. Meta-analysis statistical analyses were performed using STATA software (version 12.0, Stata Corporation, College Station, TX, USA).

\section{Results}

\section{Search results}

A total of 237 articles were identified in the initial search. After selection, ten studies involving 4779 patients met our inclusion criteria [13-22]. The details of the study selection process are shown in Fig. 1. Eight retrospective studies [13$18,20,21]$ and two prospective studies $[19,22]$ were included. No RCTs were identified. The studies were conducted in different countries as follows: the USA (5 trials) [16, 18-21], South Korea (2 trials) [13, 22], Canada (1 trial) [17], Singapore (1 trial) [15] and Israel (1 trial) [14]. The studies were published from 2011 to 2018. The mean or median patient age ranged between 50 and 69 years. Four studies compared cefazolin with nafcillin [13, 19, 20, 22], three compared cefazolin with cloxacillin $[14,15,17]$, two compared cefazolin with oxacillin $[16,18]$, and one compared cefazolin with nafcillin or oxacillin [21]. Seven studies reported the dose or duration of administration [13, 15-20]. The detailed characteristics of included studies are represented in Table 1 and Additional file 1: Table S1. Most studies included were given five or more Newcastle-Ottawa Scale stars, indicating high quality (Additional file 1: Table S2).

\section{Mortality}

All included studies reported on mortality. Our meta-analysis indicated that mortality was significant decreased in MSSA bacteremia patients treated with cefazolin compared to those treated with ASPs (OR, 0.69; 95\% CI, 0.58 to $0.82 ; \mathrm{I}^{2}=3.4 \%$ ) (Fig. 2). Sensitivity analysis was used to evaluate the robustness of the findings after exclusion of each publication (Additional file 1: Table S3). We also performed subgroups analyses based on the study design, location, study period, time of mortality reporting, control group. Most of the subgroups analyses showed that cefazolin was associated with lower mortality than ASPs, except for the studies which the control group was cloxacillin. Six studies provided adjusted mortality data after controlling for potential confounders and similar results were obtained (OR, 0.69; 95\% CI, 0.58 to $0.83 ; \mathrm{I}^{2}=23.6 \%$ ) (Table 2).

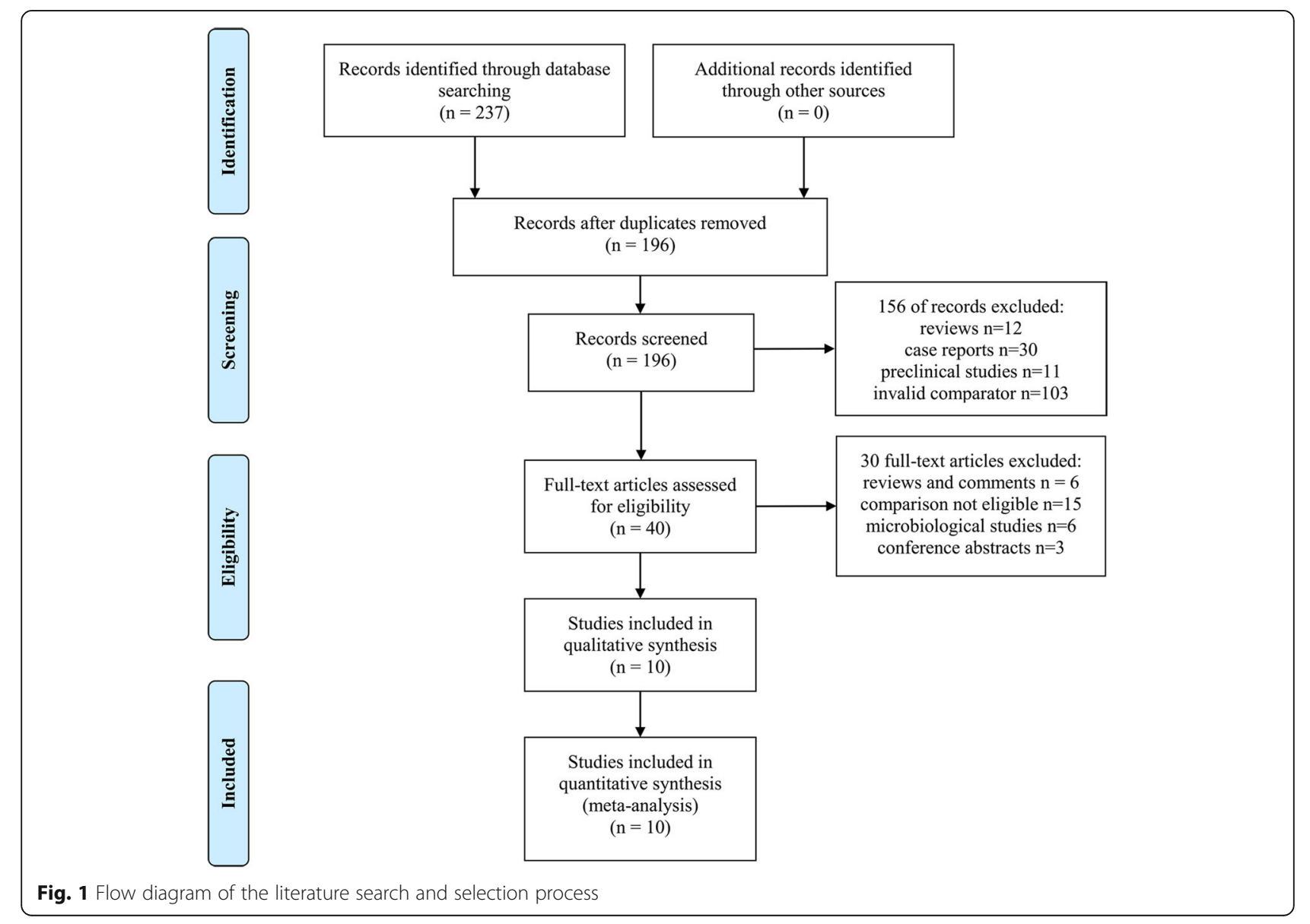


Table 1 Characteristics of the studies included in the meta-analysis

\begin{tabular}{|c|c|c|c|c|c|c|c|c|c|}
\hline Study & Design & Location & Study period & $\begin{array}{l}\text { Treatment } \\
\text { groups }\end{array}$ & $\begin{array}{l}\text { No. of } \\
\text { patients }\end{array}$ & $\begin{array}{l}\text { Median } \\
\text { dose }(\mathrm{g} / \mathrm{d})\end{array}$ & $\begin{array}{l}\text { Median } \\
\text { duration (d) }\end{array}$ & $\begin{array}{l}\text { ICU } \\
\text { admission \% }\end{array}$ & $\begin{array}{l}\text { Definition of } \\
\text { mortality }\end{array}$ \\
\hline \multirow[t]{2}{*}{$\begin{array}{l}\text { Lee } \\
2011 \text { [13] }\end{array}$} & \multirow{2}{*}{$\begin{array}{l}\text { SC retrospective } \\
\text { PS-matched } \\
\text { case- control study }\end{array}$} & \multirow[t]{2}{*}{ South Korea } & \multirow[t]{2}{*}{ 2004-2009 } & CFZ & 49 & $N R$ & 17 & $N R$ & $\begin{array}{l}\text { 30-day over } \\
\text { mortality }\end{array}$ \\
\hline & & & & NAF & 84 & NR & 15 & NR & $\begin{array}{l}\text { 90-day } \\
\text { SAB-related mortality }\end{array}$ \\
\hline \multirow[t]{2}{*}{$\begin{array}{l}\text { Paul } \\
2011[14]\end{array}$} & \multirow[t]{2}{*}{$\begin{array}{l}\text { SC retrospective } \\
\text { cohort study }\end{array}$} & \multirow[t]{2}{*}{ Israel } & \multirow[t]{2}{*}{$\begin{array}{l}\text { 1988-1994 } \\
\& 1999-2007\end{array}$} & CFZ & 72 & $N R$ & NR & \multirow[t]{2}{*}{5.2} & $\begin{array}{l}\text { 30-day all-cause } \\
\text { mortality }\end{array}$ \\
\hline & & & & $C L X$ & 281 & NR & NR & & 90-day mortality \\
\hline \multirow{2}{*}{$\begin{array}{l}\text { Renaud } \\
2011[15]\end{array}$} & \multirow{2}{*}{$\begin{array}{l}\text { SC retrospective } \\
\text { cohort study }\end{array}$} & \multirow[t]{2}{*}{ Singapore } & \multirow[t]{2}{*}{2009} & CFZ & 14 & 2 & NR & $N R$ & \multirow[t]{2}{*}{ 30-day mortality } \\
\hline & & & & $C L X$ & 13 & $2-8$ & $N R$ & NR & \\
\hline \multirow[t]{2}{*}{ Li 2014 [16] } & \multirow[t]{2}{*}{$\begin{array}{l}\text { MC retrospective } \\
\text { cohort study }\end{array}$} & \multirow[t]{2}{*}{ USA } & \multirow[t]{2}{*}{ 2008-2012 } & CFZ & 59 & 6 & 31 & 7 & $\begin{array}{l}\text { 30-day all-cause } \\
\text { mortality }\end{array}$ \\
\hline & & & & OXA & 34 & 12 & 39 & 18 & $\begin{array}{l}\text { 90-day all-cause } \\
\text { mortality }\end{array}$ \\
\hline \multirow{2}{*}{$\begin{array}{l}\text { Bai } \\
2015 \text { [17] }\end{array}$} & \multirow{2}{*}{$\begin{array}{l}\text { MC retrospective } \\
\text { PS-matched cohort } \\
\text { study }\end{array}$} & \multirow[t]{2}{*}{ Canada } & \multirow[t]{2}{*}{$2007-2010$} & CFZ & 105 & 3 & $N R$ & 10 & \multirow[t]{2}{*}{ 90-day mortality } \\
\hline & & & & $C L X$ & 249 & 12 & NR & 18 & \\
\hline \multirow{2}{*}{$\begin{array}{l}\text { Rao } \\
2015 \text { [18] }\end{array}$} & \multirow{2}{*}{$\begin{array}{l}\text { MC retrospective } \\
\text { cohort study }\end{array}$} & \multirow[t]{2}{*}{ USA } & \multirow[t]{2}{*}{ 2010-2013 } & CFZ & 103 & 6 & 29 & 41.8 & \multirow{2}{*}{$\begin{array}{l}\text { All-cause in-hospital } \\
\text { mortality }\end{array}$} \\
\hline & & & & OXA & 58 & 12 & 32.5 & 32.8 & \\
\hline \multirow{2}{*}{$\begin{array}{l}\text { Pollett } \\
2016[19]\end{array}$} & \multirow{2}{*}{$\begin{array}{l}\text { SC prospective } \\
\text { PS-matched cohort } \\
\text { study }\end{array}$} & \multirow[t]{2}{*}{ USA } & \multirow[t]{2}{*}{ 2008-2013 } & CFZ & 70 & $N R$ & 20 & 13 & \multirow{2}{*}{$\begin{array}{l}\text { 90-day all-cause } \\
\text { mortality }\end{array}$} \\
\hline & & & & NAF & 30 & $N R$ & 12 & 27 & \\
\hline \multirow{2}{*}{$\begin{array}{l}\text { Flynt } \\
2017 \text { [20] }\end{array}$} & $\mathrm{MC}$ retrospective & USA & 2013-2015 & CFZ & 68 & 6 & NR & NR & 30-day all-cause \\
\hline & cohort study & & & NAF & 81 & 12 & $N R$ & $N R$ & talı \\
\hline $\begin{array}{l}\text { McDanel } \\
2017 \text { [21] }\end{array}$ & $\begin{array}{l}\text { MC retrospective } \\
\text { cohort study }\end{array}$ & USA & 2003-2010 & CFZ & 1163 & $N R$ & $N R$ & 15 & $\begin{array}{l}\text { 30-day all-cause } \\
\text { mortality }\end{array}$ \\
\hline & & & & NAF/ OXA & 2004 & $N R$ & $N R$ & 19 & $\begin{array}{l}\text { 90-day all-cause } \\
\text { mortality }\end{array}$ \\
\hline $\begin{array}{l}\text { Lee } \\
2018 \text { [22] }\end{array}$ & $\begin{array}{l}\text { MC prospective } \\
\text { PS-matched }\end{array}$ & South Korea & 2013-2015 & CFZ & 79 & $N R$ & $N R$ & NR & $\begin{array}{l}\text { 90-day all-cause } \\
\text { mortality }\end{array}$ \\
\hline & cohort study & & & NAF & 163 & NR & $N R$ & NR & $\begin{array}{l}\text { 30-day all-cause } \\
\text { mortality }\end{array}$ \\
\hline
\end{tabular}

CFZ cefazolin, CLX cloxacillin, MC multicenter, NAF nafcillin, NR not reported, OXA oxacillin, PS propensity score, SC single center

\section{Secondary outcomes}

Clinical failure was variably defined and reported in five studies $[13,16,18,20,22]$. The cefazolin group had a significantly lower clinical failure (OR, 0.56; $95 \% \mathrm{CI}, 0.37$ to $\left.0.85 ; \mathrm{I}^{2}=44.9 \%\right)$. Eight studies reported the recurrence of bacteremia [13, 15-18, 20-22]. The results indicate no significant difference in the recurrence of bacteremia between the two groups (OR, 1.12; 95\% CI, 0.94 to $1.34 ; \mathrm{I}^{2}=0 \%$ ). Data on the number of AEs were reported in five studies $[15,16,18,20,22]$. No significant differences in AEs rates between the two group were found with high consistency (OR, 0.37; 95\% CI, 0.10 to $10.14 ; \mathrm{I}^{2}=83.1 \%$ ). The most common AEs included hepatotoxicity (e.g., elevated transaminases), nephrotoxicity (e.g., elevated serum creatinine), and hematotoxicity (e.g., leukopenia, neutropenia). There were no significant differences in the risks of anaphylaxis (OR, 0.91; 95\% CI, 0.36 to $2.99 ; \mathrm{I}^{2}=0 \%$ ) and hematotoxicity (OR, $0.56 ; 95 \% \mathrm{CI}, 0.17$ to $1.88 ; \mathrm{I}^{2}=0 \%$ ). However, we found nephrotoxicity (OR, $0.36 ; 95 \% \mathrm{CI}, 0.16$ to $0.81 ; \mathrm{I}^{2}=$ $0 \%$ ) and hepatotoxicity (OR, 0.12 ; 95\% CI, 0.04 to $0.41 ; \mathrm{I}^{2}=$ $0 \%)$ were significantly lower in the cefazolin group than in the ASPs group. Only three studies $[13,16,22]$ compared the discontinuation due to $\mathrm{AE}$. The results indicate that cefazolin was associated with lower probability of being discontinuation of treatment due to AEs compared with the ASPs (OR, 0.24; 95\% CI, 0.12 to $0.48 ; \mathrm{I}^{2}=18 \%$ ) (Table 3 and Additional file 2: Figure S1-S8).

\section{Publication bias}

Visual inspection of funnel plot showed the presence of a moderate publication bias (Fig. 3). Begg's test was not significant $(P=0.152)$, but Egger's test showed the presence of publication bias $(P=0.043)$. Fail-safe methods indicated that 56 publications would be needed to convert our estimated result. 


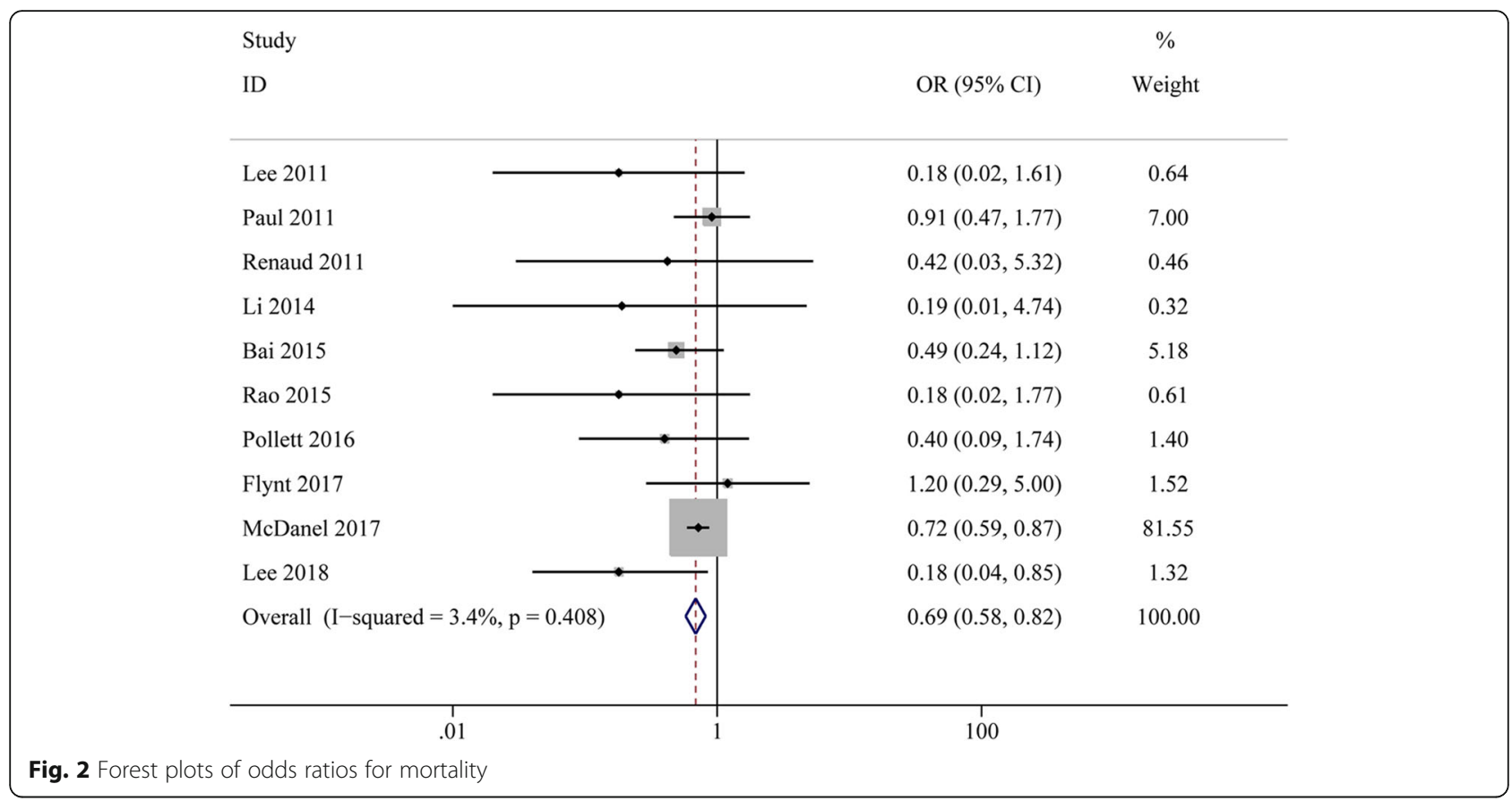

\section{Discussion}

This meta-analysis systematically reviewed studies focusing on the efficacy and safety of cefazolin and ASPs in treating bacteremia caused by MSSA. The results of our meta-analysis demonstrated that cefazolin was associated with a significant reduction in mortality and clinical failure without increasing recurrence of bacteremia, when compared to ASPs. In addition, the safety of cefazolin was superior to ASPs, especially regarding the risk of hepatotoxicity and nephrotoxicity.

Table 2 Subgroup analysis of mortality with cefazolin versus ASPs for the treatment of MSSA bacteremia

\begin{tabular}{|c|c|c|c|c|c|}
\hline Variable & No. of studies & No. of patients & OR $(95 \% \mathrm{Cl})$ & $P$ Value & $1^{2} \%$ \\
\hline \multicolumn{6}{|l|}{ Study design } \\
\hline Retrospective & 8 & 4212 & $0.71(0.59-0.84)$ & 0.57 & 0 \\
\hline Prospective & 2 & 258 & $0.27(0.09-0.79)$ & 0.46 & 0 \\
\hline \multicolumn{6}{|l|}{ Location } \\
\hline USA & 5 & 3670 & $0.71(0.59-0.86)$ & 0.52 & 0 \\
\hline Other & 5 & 800 & $0.57(0.36-0.91)$ & 0.25 & 25.4 \\
\hline \multicolumn{6}{|l|}{ Study period } \\
\hline Initiated before 2008 & 4 & 3782 & $0.58(0.36-0.92)$ & 0.15 & 43.4 \\
\hline Initiated after 2008 & 6 & 688 & $0.71(0.59-0.85)$ & 0.64 & 0 \\
\hline \multicolumn{6}{|l|}{ Mortality recording time } \\
\hline 30-day mortality & 6 & 3676 & $0.60(0.48-0.75)$ & 0.81 & 0 \\
\hline 90-day mortality & 7 & 4133 & $0.69(0.58-0.82)$ & 0.30 & 16.9 \\
\hline \multicolumn{6}{|l|}{ Adjustment } \\
\hline Propensity score matched or multiple adjusted & 6 & 4040 & $0.69(0.58-0.83)$ & 0.26 & 23.6 \\
\hline Unadjusted & 10 & 4779 & $0.74(0.64-0.87)$ & 0.11 & 37.6 \\
\hline \multicolumn{6}{|l|}{ Control group } \\
\hline NAF or OXA & 7 & 3910 & $0.69(0.57-0.83)$ & 0.26 & 22.6 \\
\hline CLX & 3 & 560 & $0.69(0.42-1.12)$ & 0.46 & 0 \\
\hline
\end{tabular}

ASPs antistaphylococcal penicillins, CFZ cefazolin, Cl confidence interval, CLX cloxacillin, MSSA methicillin-susceptible Staphylococcus aureus, NAF nafcillin, OR odds ratio, OXA oxacillin 
Table 3 Meta-analysis of each secondary outcome

\begin{tabular}{|c|c|c|c|c|c|c|}
\hline Outcome & No. of studies & No. of patients & OR $(95 \% \mathrm{Cl})$ & $P$ Value & $2^{2} \%$ & Effects model \\
\hline Clinical failure & 5 & 778 & $0.56(0.37-0.85)$ & 0.12 & 44.9 & Fixed \\
\hline Recurrence of bacteremia & 8 & 4017 & $1.12(0.94-1.34)$ & 0.80 & 0 & Fixed \\
\hline AEs & 5 & 672 & $0.37(0.10-1.41)$ & 0 & 83.1 & Random \\
\hline Hepatotoxicity & 4 & 645 & $0.12(0.04-0.41)$ & 0.51 & 0 & Fixed \\
\hline Nephrotoxicity & 3 & 484 & $0.36(0.16-0.81)$ & 0.88 & 0 & Fixed \\
\hline Anaphylaxis & 5 & 672 & $0.91(0.36-2.99)$ & 0.53 & 0 & Fixed \\
\hline Hematotoxicity & 4 & 511 & $0.56(0.17-1.88)$ & 0.42 & 0 & Fixed \\
\hline Discontinuation due to AEs & 3 & 468 & $0.24(0.12-0.48)$ & 0.30 & 18 & Fixed \\
\hline
\end{tabular}

$A E s$ adverse effects, $\mathrm{Cl}$ confidence interval, $\mathrm{OR}$ odds ratio

The results of the primary outcome were robust and were not significantly altered during most of the subgroup and sensitivity analyses. A subgroup analysis based on the control group showed that the non-significant association in the analysis of the studies in which the control group was cloxacillin could be due to lack of power, as the trend towards lower mortality with cefazolin was evident. Although Egger's test showed significant publication bias, the fail-safe number was large enough $(n=56)$.

Regarding the safety profile, this present study supported the superior tolerability of cefazolin over ASPs. A recent meta-analysis (published after completion of our work) also reviewed the literature comparing the safety of cefazolin and ASPs for the treatment of MSSA infections [23]. Although the previous meta-analysis focused on MSSA infections but not MSSA bacteremia, these results are consistent with our findings. The results of this study showed that cefazolin was associated with lower rates of nephrotoxicity and hepatotoxicity compared with ASPs among hospitalized patients or outpatients treated for MSSA infections. Moreover, cefazolin was associated with lower probability of discontinuation due to AEs in hospitalized patients and hypersensitivity reactions in outpatients [23].

In clinical practice, the preference for ASPs over cefazolin for MSSA bacteremia is primarily due to concerns about the inoculum effect. The inoculum effect has been defined as a significant elevation in the cefazolin minimum inhibitory concentration with an inoculum higher than standard bacterial inoculum [24]. This is usually due to the production of a type A $\beta$-lactamase that can hydrolyze cefazolin [25]. Two recent review articles summarized clinical reports focused on cefazolin inoculum effect $[9,10]$. However, most of these reports are case reports or case series and no study show any significant difference in outcomes when comparing isolates

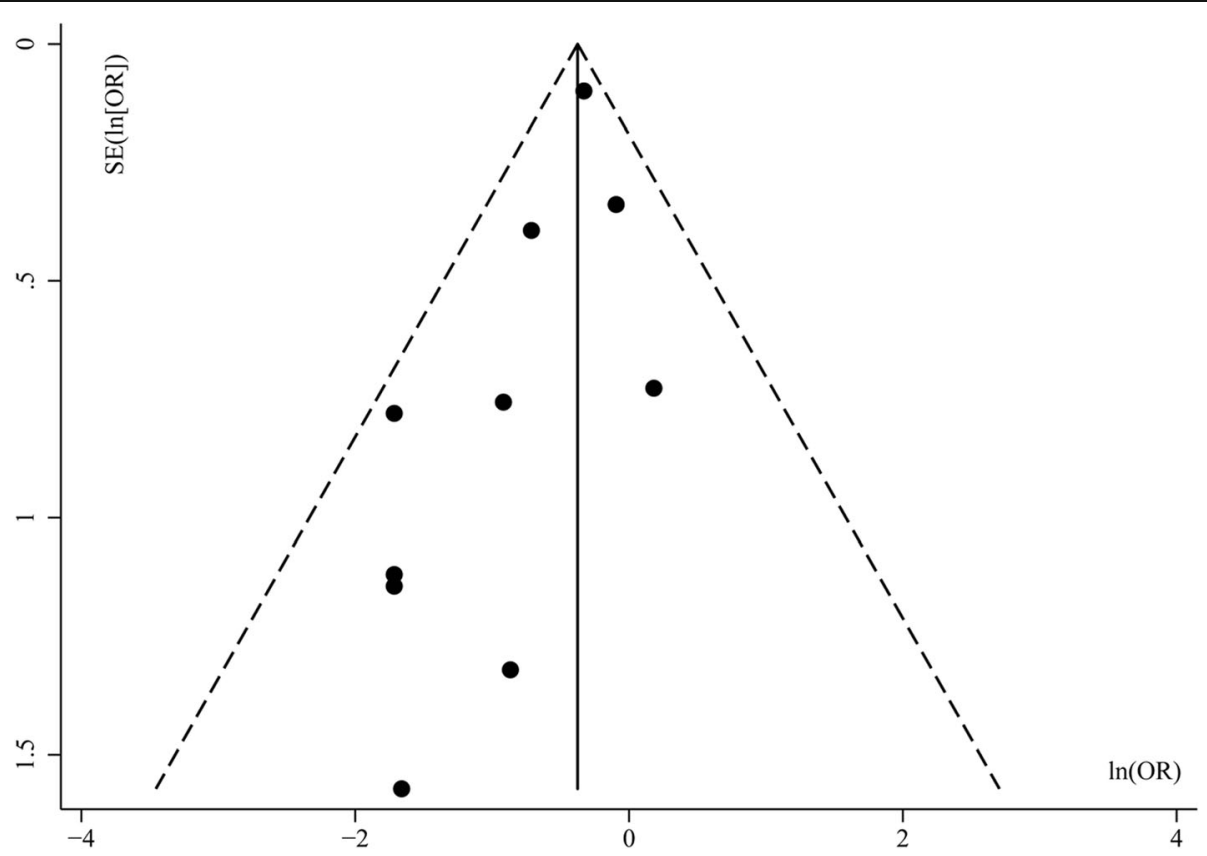

Fig. 3 Funnel plots of mortality 
with or without the inoculum effect [26-28]. A recent study by Lee et al. found that treatment failure $(61.5 \%$ vs. $28.9 \%)$ and mortality ( $15.4 \%$ vs. $0 \%$ ) were significantly higher in the inoculum effect-positive arm than in the negative arm among patients who received cefazolin [22]. Therefore, the clinical relevance of the cefazolin inoculum effect is still unclear. More properly designed studies comparing cefazolin to ASPs for high-inoculum MSSA bacteremia, such as endocarditis, are required.

The selection of a regimen for the treatment of MSSA bacteremia is primarily based on efficacy, safety, costs and availability. In addition to the reduction in mortality, clinical failure, risks of hepatotoxicity and nephrotoxicity, and the probability of discontinuation due to AEs as noted above, cefazolin offers several additional advantages such as being less expensive and being more convenient to dose $[15,18]$. Taken together, the evidence of supports a beneficial effect of cefazolin over ASPs for MSSA bacteremia in the absence of endocarditis or high-burden infection.

Two recent meta-analyses (both published after completion of our work) have compared the use of cefazolin and ASPs for the treatment of MSSA bacteremia [29, 30]. The conclusions of these two meta-analyses were similar and consistent: the survival rates and safety profiles of cefazolin were superior to ASPs. The meta-analysis conducted by Bidell et al. concluded that cefazolin was associated with a significant reduction in all-cause 90-day mortality (OR, $0.63 ; 95 \% \mathrm{CI}, 0.41$ to $0.99 ; \mathrm{I}^{2}=58 \%$ ) and discontinuation due to AEs (OR, 0.25; 95\% CI, 0.11 to 0.56; $\mathrm{I}^{2}=13 \%$ ), when compared to ASPs [29]. Another meta-analysis conducted by Rindone et al. demonstrated that the mortality (RR, $0.78 ; 95 \% \mathrm{CI}, 0.69-0.88 ; \mathrm{I}^{2}=51 \%$ ) and withdrawals from AEs (RR, 0.27; 95\% CI, 0.16 to 0.47 ; $\mathrm{I}^{2}=37 \%$ ) were significantly lower in the cefazolin group than in the ASPs group [30]. These two meta-analyses had some differences compared with ours: (i) these two previous meta-analyses did not report the differences in AEs rates. Our study compared the differences in AEs (e.g., hepatotoxicity, nephrotoxicity, hematotoxicity, and anaphylaxis) between the cefazolin and ASPs and concluded the safety of cefazolin was superior to ASPs, especially regarding the risk of hepatotoxicity and nephrotoxicity; (ii) our meta-analysis demonstrated that the clinical failure was significantly lower in the cefazolin group than in the ASPs group. However, the meta-analysis by Bidell et al. found no significant differences in clinical failure rate between the two groups [29]. The difference may be due to the included studies. Of note, the meta-analysis conducted by Bidell et al. included only seven out of the ten observational studies analyzed in our meta-analysis. Moreover, two original studies $[17,21]$ included in the meta-analysis did not report the clinical failure rate. However, these two original studies were used in the analysis of clinical failure in the meta-analysis conducted by Bidell et al. [29]; (iii) all analyses were conducted unadjusted in these two previous meta-analyses. It is commonly believed that adjusted estimates are consistently closer to the true values than unadjusted estimates. The present meta-analysis used the adjusted estimates if appropriate and presented separate subgroup analyses of adjusted or unadjusted estimates.

There were several limitations that should be considered. First, all studies included in the present meta-analysis were observational studies, which have a high selection bias and may expose the analysis to confounders. For example, patients in the ASPs treatment arms had numerically higher rates of endocarditis $[13,17,18,20,22]$ and ICU admission $[16,17,19,21]$. The subgroup analysis of the adjusted odds ratios of primary outcome continued to favor cefazolin. Although these publications tried to adjust for the confounders, residual confounding factors remain. Second, despite the absence of statistical heterogeneity, the inherent heterogeneity across the studies analyzed (i.e., source of bacteremia, source control, dose and duration, etc.) should not be discounted. Third, as the source of bloodstream infection were diverse in the present study, we could not conclude that cefazolin was superior to ASPs for a specific type of bacteremia, especially in deep-seated infection, such as endocarditis.

\section{Conclusion}

The results of present study favor the application of cefazolin for the treatment of MSSA bacteremia. Therefore, we suggest that cefazolin be used as a first-line regimen for MMSA bacteremia in the absence of endocarditis or high-burden infection. Our study should be regarded as important evidence to help make clinical decisions in choosing a treatment option for MSSA bacteremia.

\section{Additional files}

Additional file 1: Table S1. Characteristics of the studies included in the meta-analysis. Table S2. Quality of assessment for included studies. Table S3. Sensitivity analysis assessing mortality. (DOCX $24 \mathrm{~kb}$ )

Additional file 2: Forest plots of odds ratios for second outcomes (see in Figure S1-S8). (DOCX 11351 kb)

\section{Abbreviations}

AEs: Adverse effects; ASPs: Antistaphylococcal penicillins; CFZ: Cefazolin Cls: Confidence intervals; CLX: Cloxacillin; MC: Multicenter; MRSA: Methicillinresistant Staphylococcus aureus; MSSA: Methicillin-susceptible Staphylococcus aureus; NAF: Nafcillin; NOS: Newcastle-Ottawa scale; NR: Not reported; OR: Odds ratio; OXA: Oxacillin; PS: Propensity score; SC: Single center

\section{Funding}

This work was supported by Zhejiang Provincial Program for the Cultivation of High-level Innovative Health Talents (grant number: 2010-190-4), Clinical Pharmacy of Zhejiang Medical Key Discipline (grant number: 2018-2-3) and Clinical Pharmacy of Hangzhou Medical Key Discipline (grant number: 2017-68-7). 


\section{Availability of data and materials}

All data generated or analyzed during this study are included in this published article and its supplementary information files.

\section{Authors' contributions}

Conceived and designed the protocol: LNM and SCC. Execution of literature search: SCC and XYB. Execution of data extraction: SCC and WJ. Execution of quality assessment: XYB and ZQ. Data analysis and interpretation: SCC, ZQ, LQY and WF. All authors have read and approved the final manuscript.

\section{Ethics approval and consent to participate}

Not applicable.

\section{Consent for publication}

Not applicable.

\section{Competing interests}

The authors declare that they have no competing interests.

\section{Publisher's Note}

Springer Nature remains neutral with regard to jurisdictional claims in published maps and institutional affiliations.

\section{Author details}

'Department of Clinical Pharmacy, Affiliated Hangzhou First People's Hospital, Zhejiang University School of Medicine, Hangzhou, China. ${ }^{2}$ Department of Clinical Pharmacy, Hangzhou First People's Hospital, Nanjing Medical University, Hangzhou, China. ${ }^{3}$ Department of Pharmacometrics, Mosim Co., Ltd, Shanghai, China. ${ }^{4}$ Department of Pharmacy, Hangzhou Obstetrics \& Gynecology Hospital, Hangzhou, China. ${ }^{5}$ Department of Clinical Pharmacology, Translational Medicine Research Center, Affiliated Hangzhou First People's Hospital, Zhejiang University School of Medicine, Hangzhou, China.

Received: 9 May 2018 Accepted: 27 September 2018

\section{Published online: 11 October 2018}

\section{References}

1. Laupland KB, Lyytikäinen O, Søgaard M, Kennedy KI, Knudsen JD, Ostergaard C, et al. The changing epidemiology of Staphylococcus aureus bloodstream infection: a multinational population-based surveillance study Clin Microbiol Infect. 2013;19:465-71.

2. Cosgrove SE, Sakoulas G, Perencevich EN, Schwaber MJ, Karchmer AW, Carmeli Y. Comparison of mortality associated with methicillinresistant and methicillin-susceptible Staphylococcus aureus bacteremia: a meta-analysis. Clin Infect Dis. 2003;36:53-9.

3. McDanel JS, Perencevich EN, Diekema DJ, Herwaldt LA, Smith TC, Chrischilles EA, et al. Comparative effectiveness of beta-lactams versus vancomycin for treatment of methicillin-susceptible Staphylococcus aureus bloodstream infections among 122 hospitals. Clin Infect Dis. 2015;61:361-7.

4. Wong $D$, Wong $T$, Romney M, Leung V. Comparative effectiveness of $\beta$ lactam versus vancomycin empiric therapy in patients with methicillinsusceptible Staphylococcus aureus (MSSA) bacteremia. Ann Clin Microbiol Antimicrob. 2016:15:27.

5. Baddour LM, Wilson WR, Bayer AS, Fowler VG Jr, Tleyjeh IM, Rybak MJ, et al. Infective endocarditis in adults: diagnosis, antimicrobial therapy, and management of complications: a scientific statement for healthcare professionals from the american heart association. Circulation. 2015;132: 1435-86.

6. Gudiol F, Aguado JM, Almirante B, Bouza E, Cercenado E, Domínguez MÁ, et al. Diagnosis and treatment of bacteremia and endocarditis due to Staphylococcus aureus. A clinical guideline from the Spanish Society of Clinical Microbiology and Infectious Diseases (SEIMC). Enferm Infecc Microbiol Clin. 2015;33(625):e1-e23.

7. Liu C, Bayer A, Cosgrove SE, Daum RS, Fridkin SK, Gorwitz RJ, et al. Clinical practice guidelines by the infectious diseases society of america for the treatment of methicillin-resistant Staphylococcus aureus infections in adults and children. Clin Infect Dis. 2011;52:e18-55.

8. Mermel LA, Allon M, Bouza E, Craven DE, Flynn P, O'Grady NP, et al. Clinical practice guidelines for the diagnosis and management of intravascular catheter-related infection: 2009 update by the Infectious Diseases Society of America. Clin Infect Dis. 2009:49:1-45.

9. Li J, Echevarria KL, Traugott KA. $\beta$-Lactam therapy for methicillinsusceptible Staphylococcus aureus bacteremia: a comparative review of cefazolin versus antistaphylococcal penicillins. Pharmacotherapy. 2017;37: $346-60$.

10. Loubet P, Burdet C, Vindrios W, Grall N, Wolff M, Yazdanpanah Y, et al. Cefazolin versus anti-staphylococcal penicillins for treatment of methicillinsusceptible Staphylococcus aureus bacteraemia: a narrative review. Clin Microbiol Infect. 2018;24:125-32.

11. Higgins JPT, Green S. Cochrane handbook for systematic reviews of interventions. Version 5.1.0. Cochrane Collaboration. 2011. https://handbook5-1.cochrane.org.

12. Stang A. Critical evaluation of the Newcastle-Ottawa scale for the assessment of the quality of nonrandomized studies in meta-analyses. Eur J Epidemiol. 2010;25:603-5.

13. Lee S, Choe PG, Song KH, Park SW, Kim HB, Kim NJ, et al. Is cefazolin inferior to nafcillin for treatment of methicillin-susceptible Staphylococcus aureus bacteremia? Antimicrob Agents Chemother. 2011:55:5122-6.

14. Paul M, Zemer-Wassercug $N$, Talker O, Lishtzinsky $Y$, Lev B, Samra Z, et al. Are all beta-lactams similarly effective in the treatment of methicillinsensitive Staphylococcus aureus bacteraemia? Clin Microbiol Infect. 2011;17:1581-6.

15. Renaud CJ, Lin X, Subramanian S, Fisher DA. High-dose cefazolin on consecutive hemodialysis in anuric patients with staphylococcal bacteremia. Hemodial Int. 2011;15:63-8.

16. Li J, Echevarria KL, Hughes DW, Cadena JA, Bowling JE, Lewis JS 2nd. Comparison of cefazolin versus oxacillin for treatment of complicated bacteremia caused by methicillin-susceptible Staphylococcus aureus. Antimicrob Agents Chemother. 2014:58:5117-24.

17. Bai AD, Showler A, Burry L, Steinberg M, Ricciuto DR, Fernandes T, et al. Comparative effectiveness of cefazolin versus cloxacillin as definitive antibiotic therapy for MSSA bacteraemia: results from a large multicentre cohort study. J Antimicrob Chemother. 2015;70:1539-46.

18. Rao SN, Rhodes NJ, Lee BJ, Scheetz MH, Hanson AP, Segreti J, et al. Treatment outcomes with cefazolin versus oxacillin for deep-seated methicillin-susceptible Staphylococcus aureus bloodstream infections. Antimicrob Agents Chemother. 2015:59:5232-8.

19. Pollett S, Baxi SM, Rutherford GW, Doernberg SB, Bacchetti P, Chambers HF. Cefazolin versus Nafcillin for methicillin-sensitive Staphylococcus aureus bloodstream infection in a California tertiary medical center. Antimicrob Agents Chemother. 2016;60:4684-9.

20. Flynt LK, Kenney RM, Zervos MJ, Davis SL. The safety and economic impact of cefazolin versus Nafcillin for the treatment of methicillinsusceptible Staphylococcus aureus bloodstream infections. Infect Dis Ther. 2017;6:225-31.

21. McDanel JS, Roghmann MC, Perencevich EN, Ohl ME, Goto M, Livorsi DJ, et al. Comparative effectiveness of cefazolin versus nafcillin or oxacillin for treatment of methicillin-susceptible Staphylococcus aureus infections complicated by bacteremia: a nationwide cohort study. Clin Infect Dis. 2017:65:100-6.

22. Lee S, Song KH, Jung SI, Park WB, Lee SH, Kim YS, et al. Comparative outcomes of cefazolin versus nafcillin for methicillin-susceptible Staphylococcus aureus bacteraemia: a prospective multicentre cohort study in Korea. Clin Microbiol Infect. 2018:24:152-8.

23. Eljaaly K, Alshehri S, Erstad BL. Systematic review and meta-analysis of the safety of Antistaphylococcal Penicillins compared to cefazolin. Antimicrob Agents Chemother. 2018. https://doi.org/10.1128/AAC.01816-17.

24. Soriano F, García-Corbeira P, Ponte C, Fernández-Roblas R, Gadea I. Correlation of pharmacodynamic parameters of five beta-lactam antibiotics with therapeutic efficacies in an animal model. Antimicrob Agents Chemother. 1996:40:2686-90

25. Lee SH, Park WB, Lee S, Park S, Kim SW, Lee JM, et al. Association between type a blaZ gene polymorphism and cefazolin inoculum effect in methicillin-susceptible Staphylococcus aureus. Antimicrob Agents Chemother. 2016:60:6928-32

26. Nannini EC, Stryjewski ME, Singh KV, Bourgogne A, Rude TH, Corey GR, et al. Inoculum effect with cefazolin among clinical isolates of methicillin-susceptible Staphylococcus aureus: frequency and possible cause of cefazolin treatment failure. Antimicrob Agents Chemother. 2009:53:3437-41. 
27. Chong YP, Park SJ, Kim ES, Bang KM, Kim MN, Kim SH, et al. Prevalence of blaZ gene types and the cefazolin inoculum effect among methicillinsusceptible Staphylococcus aureus blood isolates and their association with multilocus sequence types and clinical outcome. Eur J Clin Microbiol Infect Dis. 2015;34:349-55.

28. Lee S, Kwon KT, Kim HI, Chang HH, Lee JM, Choe PG, et al. Clinical implications of cefazolin inoculum effect and $\beta$-lactamase type on methicillin-susceptible Staphylococcus aureus bacteremia. Microb Drug Resist. 2014;20:568-74.

29. Bidell MR, Patel N, O'Donnell JN. Optimal treatment of MSSA bacteraemias: a meta-analysis of cefazolin versus antistaphylococcal penicillins. J Antimicrob Chemother. 2018. https://doi.org/10.1093/jac/dky259.

30. Rindone JP, Mellen CK. Meta-analysis of trials comparing cefazolin to antistaphylococcal penicillins in the treatment of methicillin-sensitive Staphylococcus aureus bacteraemia. Br J Clin Pharmacol. 2018;84:1258-66.

Ready to submit your research? Choose BMC and benefit from:

- fast, convenient online submission

- thorough peer review by experienced researchers in your field

- rapid publication on acceptance

- support for research data, including large and complex data types

- gold Open Access which fosters wider collaboration and increased citations

- maximum visibility for your research: over $100 \mathrm{M}$ website views per year

At BMC, research is always in progress.

Learn more biomedcentral.com/submissions 